\title{
Risk analysis with the usage of IT system TURAWA
}

\author{
Marta Woch ${ }^{1, *}$, Justyna Tomaszewska ${ }^{2, * *}$, Jarosław Wójcik ${ }^{3, * * *}$, and Mariusz Zieja ${ }^{4, * * * *}$ \\ ${ }^{1}$ Faculty of Power and Aeronautical Engineering, Division of Fundamentals of Machine Design, Warsaw University of Technology, \\ Warsaw, Poland \\ ${ }^{2}$ Faculty of Aviation, Polish Air Force Academy, Dęblin, Poland \\ ${ }^{3}$ Faculty of Cybernetics, Military University of Technology, Warsaw, Poland \\ ${ }^{4}$ Division for IT Support of Logistics, Air Force Institute of Technology, Warsaw, Poland
}

\begin{abstract}
In the time of globalization and the continuous travelling of people between different parts of the world, air transportation is becoming one of the most important modes of transport. Nevertheless, it is crucial to continuously improve the level of safety and reduce the absolute number of accidents and their victims. The risk analysis with the usage of IT system TURAWA, which was developed to collect the aircraft's accidents informations, has been discussed in the presented article. Calculation of risk is based on the data sample collected in the operation process. The implementation of the risk of potential failure event in TURAWA is presented and compared with the prediction of such situation by the decision trees. It has been concluded that models should be developed, which cause in the elimination of the human factor from the decision making chain.
\end{abstract}

\section{Introduction}

All industrial sectors have been under increasing cost pressure in recent years. The policy for the aviation industry is being progressively replaced by companies controlling Quality Management Systems with the use of state regulations. The International Civil Aviation Organization (ICAO) has developed the Safety Management System (SMS), which is applicable to various aviation organisations, including airlines and airports [1,2].

Air traffic services is one of the most important elements in the process of performing aviation tasks regardless of the type of flight. Priority shall be given to the process of safe flight due to its consequences [3, 4].

The risk management system is a fundamental element of the safety management approach. In this system all operational processes and procedures, that are acceptable for safety requirements, are described. An operational system consists of aeronautical organisational structures, processes and procedures, people, equipment and devices [5].

Since 2011, IT system TURAWA has been used in the Polish Air Force, which brings together the various users of the institutions and military units in a coherent operating system on a computer network. IT system TURAWA has the ability to enter preventive flight safety documents and to gather the information of flight crew, flight operations, and occurrences [6].

\footnotetext{
*e-mail: marta.woch@itwl.pl

**e-mail: j.tomaszewska@wsosp.pl

***e-mail: jaroslaw.wojcik@itwl.pl

****e-mail: mariusz.zieja@itwl.pl
}

\section{Formulation of the problem}

Safety risk management is one of the key component of a safety management system. The term safety risk management is meant to differentiate this function from the management of financial risk, legal risk, economic risk and so forth [7, 8]. Safety risk is the projected likelihood and severity of the consequence or outcome from an existing hazard or situation. The process of controlling safety risks starts by assessing the probability that the consequences of hazards will materialize during aviation activities performed by the organization. Safety risk probability is defined as the likelihood or frequency that a safety consequence or outcome might occur.

A typical safety risk probability table, in this case, a five-point table, is presented in the table 1 . The table includes five categories to denote the probability related to an unsafe event or condition, the description of each category, and an assignment of a value to each category.

Table 1. Safety risk probability table [7]

\begin{tabular}{lll}
\hline Likelihood & Meaning & Value \\
\hline Frequent & $\begin{array}{l}\text { Likely to occur many times } \\
\text { (has occurred frequently) }\end{array}$ & 5 \\
\hline Occasional & $\begin{array}{l}\text { Likely to occur sometimes (has } \\
\text { occurred infrequently) }\end{array}$ & 4 \\
\hline Remote & $\begin{array}{l}\text { Unlikely to occur, but possible } \\
\text { (has occurred rarely) }\end{array}$ & 3 \\
\hline Improbable & $\begin{array}{l}\text { Very unlikely to occur (not } \\
\text { known to have occurred) }\end{array}$ & 2 \\
\hline $\begin{array}{l}\text { Extremely } \\
\text { improbable }\end{array}$ & $\begin{array}{l}\text { Almost inconceivable that the } \\
\text { event will occur }\end{array}$ & 1 \\
\hline
\end{tabular}


Once the probability assessment has been completed, the next step is to assess the safety risk severity, taking into account the potential consequences related to the hazard. Safety risk severity is defined as the extent of harm that might reasonably occur as a consequence or outcome of the identified hazard [7].

The severity assessment should consider all possible consequences related to an unsafe condition or object, taking into account the worst foreseeable situation. Table 2 presents a typical safety risk severity table.

Table 2. Safety risk severity table [7]

\begin{tabular}{|c|c|c|}
\hline Severity & Meaning & Value \\
\hline Catastrophic & $\begin{array}{l}\text { - Equipment destroyed } \\
\text { - Multiple deaths }\end{array}$ & A \\
\hline Hazardous & $\begin{array}{l}\text { - A large reduction in safety } \\
\text { margins, physical distress or a } \\
\text { workload such that the opera- } \\
\text { tors cannot be relied upon to } \\
\text { perform their tasks accurately } \\
\text { or completely } \\
\text { - Serious injury } \\
\text { - Major equipment damage }\end{array}$ & B \\
\hline Major & $\begin{array}{l}\text { - A significant reduction in } \\
\text { safety margins, a reduction in } \\
\text { the ability of the operators to } \\
\text { cope with adverse operating } \\
\text { conditions as a result of an } \\
\text { increase in workload or as a } \\
\text { result of conditions impairing } \\
\text { their efficiency } \\
\text { - Serious incident } \\
\text { - Injury to persons }\end{array}$ & $\mathrm{C}$ \\
\hline Minor & $\begin{array}{l}\text { - Nuisance } \\
\text { - Operating limitations } \\
\text { - Use of emergency procedures } \\
\text { - Minor incident }\end{array}$ & $\mathrm{D}$ \\
\hline Negligible & - Few consequences & $\mathrm{E}$ \\
\hline
\end{tabular}

The safety risk probability and severity assessment process can be used to derive a safety risk index. The index created through the methodology described above consists of an alphanumeric designator, indicating the combined results of the probability and severity assessments. The respective severity/probability combinations are presented in the safety risk assessment matrix in figure 1.

\subsection{IT system TURAWA}

Lack of an effective and reliable information sub-system, practically excludes any sensible actions, was one of the reason to give grounds for a complex system to analyse and assess flight safety. The system intended for the aviation of the Armed Forces of the Republic of Poland will be made operative under the name TURAWA. Efforts to develop this system were started in ITWL (Air Force Institute of Technology) in 2003. Prediction and expectation

\begin{tabular}{|c|c|c|c|c|c|}
\hline \multirow{2}{*}{$\begin{array}{c}\text { Risk } \\
\text { probability }\end{array}$} & \multicolumn{5}{|c|}{ Risk severity } \\
\hline & $\begin{array}{c}\text { Catastrophic } \\
\text { A }\end{array}$ & $\begin{array}{c}\text { Hazardous } \\
\text { B }\end{array}$ & $\begin{array}{l}\text { Major } \\
\mathrm{C}\end{array}$ & $\begin{array}{c}\text { Minor } \\
\text { D }\end{array}$ & $\begin{array}{l}\text { Negligible } \\
\mathrm{E}\end{array}$ \\
\hline Frequent & $5 A$ & 5B & $5 C$ & 5D) & 5틀 \\
\hline Occasional & 4A & 4B & $\mathbb{A C}$ & $4 D$ & 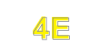 \\
\hline Remote & $3 A$ & 3圆 & $3 C$ & $3 D$ & $3 E$ \\
\hline Improbable & 2A & 28 & $2 C$ & 2D & 2E \\
\hline $\begin{array}{l}\text { Extremely } \\
\text { improbable }\end{array}$ & 1爬 & 1B & $1 C$ & 1D & 1E \\
\hline
\end{tabular}

Figure 1. Safety risk assessment matrix

say about 2007 as the year of putting the system into service after some test operation.

The TURAWA system is fully functional within a computer network. It has been designed using a three-layer architecture, with the following layers to be distinguished:

- the customer's layer that includes the system users' computers, each of them furnished with the www browser,

- the applications layer, i.e. a server that contains the system's logic,

- the database layer accomplished by means of the database server that stores the recorded data.

\subsection{Airworthiness Risk Acceptance Matrix}

Risk is the potential for losses and rewards as a result of a failure event. Risk is a characteristic of an uncertain future, and not of either the present or past. When uncertainties are resolved, or the future becomes the present, risk becomes nonexistent. Risk does not exist for historical events or events that are currently happening [9]. Risk is evaluated in terms of both the probability of occurrence and the impact of the occurrence. The United States Air Force (USAF) uses a matrix to determine the risk in terms of a Hazard Risk Index (HRI) as shown in figure 2 [10].

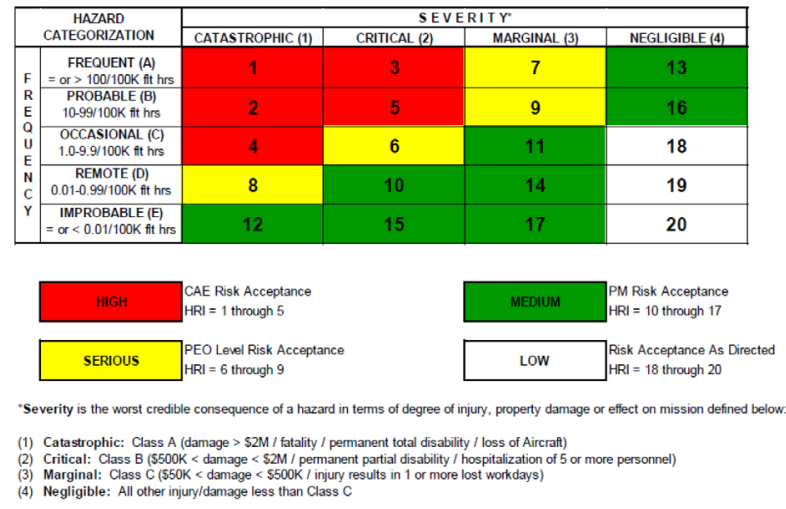

Figure 2. USAF Airworthiness Risk Acceptance Matrix 
In Polish Air Force the Airworthiness Risk Acceptance Matrix is used in the form presented in figure 3. The Airworthiness Risk Acceptance Matrix is implemented in the IT system TURAWA, which support the decision process.

\begin{tabular}{|c|c|c|c|c|c|c|}
\hline \multirow{2}{*}{\multicolumn{2}{|c|}{$\begin{array}{c}\text { Hazard } \\
\text { categorization }\end{array}$}} & \multicolumn{5}{|c|}{ Frequency } \\
\hline & & Frequent & Probable & Occasional & Remote & Improbable \\
\hline \multirow{4}{*}{ 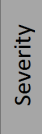 } & Catastrophic & 20 & 19 & 17 & 13 & 11 \\
\hline & Critical & 18 & 15 & 14 & 8 & 5 \\
\hline & Marginal & 16 & 10 & 9 & 5 & 3 \\
\hline & Negligible & 12 & 7 & 6 & 2 & 1 \\
\hline
\end{tabular}
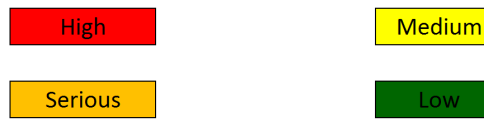

Serious

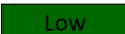

Figure 3. Polish Air Force Airworthiness Risk Acceptance Matrix

The Airworthiness Risk Acceptance Matrix method is insufficient to assess the risks of safety aircraft operation, therefore other, statistical methods are proposed.

Figure 4 shows the implementation, together with the interface, of the Airworthiness Risk Acceptance Matrix.

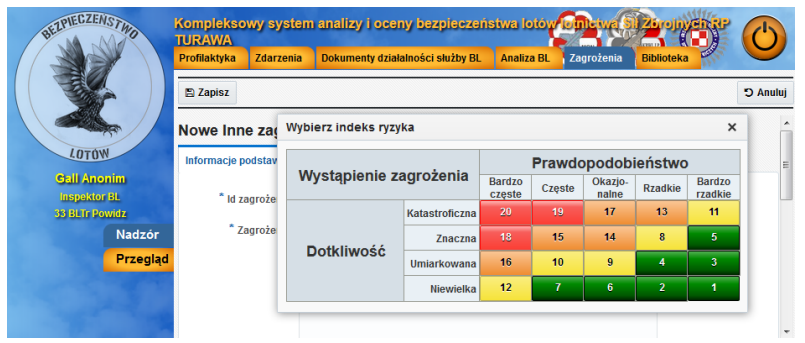

Figure 4. Airworthiness Risk Acceptance Matrix implemented in IT system TURAWA

\subsection{Decision trees}

The breakthrough of this contribution was the application of methods, such as decision trees, applied in other fields of science.

Decision trees are a class of predictive data mining tools which predict either a categorical or continuous response variable. They get their name from the structure of the models built. A series of decisions are made to segment the data into homogeneous subgroups. This is also called recursive partitioning. If presented graphically, the model can resemble a tree with branches [11].

A decision tree is composed of nodes and splits of the data. The tree starts with all training data residing in the first node. An initial division is made using a predictor variable, segmenting the data into 2 or more child nodes. Divisions can then be made from the child nodes. A terminal node is the one where no more divisions are made. Predictions are made based on the behaviour of terminal nodes [12].
Table 3. Flight parameters.

\begin{tabular}{|c|c|c|}
\hline Variable name & unit & type \\
\hline Time after sunrise & $\min$ & Continuous \\
\hline Time after sunset & $\min$ & Continuous \\
\hline Month & & Categorical \\
\hline Aircraft type & & Categorical \\
\hline Age of aircraft & day & Continuous \\
\hline Atmospheric conditions & & Categorical \\
\hline Name of the military department & & Categorical \\
\hline Real time in air & $\min$ & Continuous \\
\hline Number of crew members & & Continuous \\
\hline Flight-hour of the first pilot & hour & Continuous \\
\hline $\begin{array}{l}\text { Flight-hour of the first pilot } \\
\text { performed on a given aircraft type }\end{array}$ & hour & Continuous \\
\hline $\begin{array}{l}\text { Year of the promotion of the first } \\
\text { pilot }\end{array}$ & & Continuous \\
\hline $\begin{array}{l}\text { Subsequent departure of the first } \\
\text { pilot on a given day }\end{array}$ & & Continuous \\
\hline
\end{tabular}

Decision trees offer many advantages. One important advantage is the ease of interpretation of a decision tree. While the tree can be complex, involving a large number of splits and nodes, users can interpret the model [13]. Additionally, making model predictions does not involve mathematical calculations as in General Linear Models. The predictions are based on decision rules. In classification problems, the user can specify misclassification cost. Decision trees tend to give good predictive accuracy and can allow for missing data in deployment [14].

On the other hand, decision trees have such disadvantages as: most of the algorithms require that the target attribute will have only discrete values, or as decision trees use the "divide and conquer" method, they tend to perform well if a few highly relevant attributes exist, but less so if many complex interactions are present.

\subsection{Decision trees results}

In order to carry out experimental studies, flights performed on a third generation fighter aircraft were considered. The data were derived from the last 6 years of operation exploitation process in Poland. Flights were analysed in terms of incidents or undesirable events occurrences $[15,16]$.

Table 3 presents variables, which represent the examined flight parameters.

Evaluation of the performance of a classification model is based on the counts of test records correctly and incorrectly predicted by the model. These counts are tabulated in a table known as a confusion matrix [17].

Although a confusion matrix provides the information needed to determine how well a classification models perform, summarizing this information with a single number would make it more convenient. This can be done using a performance metric such as accuracy, which is defined as follows:

$$
\text { accuracy }=\frac{\text { Number of correct predictions }}{\text { Total number of predictions }}
$$




$$
\text { error rate }=\frac{\text { Number of wrong predictions }}{\text { Total number of predictions }}
$$

In this analysis, $80 \%$ of the cases were selected as the testing samples.

Table 4 and 5 shows the percentage of correct decisions for the training sample and the learning sample, respectively.

Table 4. Cross tabulation for training sample.

\begin{tabular}{|c|c|c|}
\hline Reality $\quad$ Model & no incident & incident \\
\hline no incident & $66.07 \%$ & $27.52 \%$ \\
\hline incident & $0.66 \%$ & $5.75 \%$ \\
\hline
\end{tabular}

Table 5. Cross tabulation for testing sample.

\begin{tabular}{|c|c|c|}
\hline $\begin{array}{ll}\text { Reality } & \text { Model }\end{array}$ & no incident & incident \\
\hline no incident & $59.24 \%$ & $33.61 \%$ \\
\hline incident & $2.94 \%$ & $4.20 \%$ \\
\hline
\end{tabular}

In the failure prediction matrix the correct prediction was in more then $70 \%$ for training sample (Table reft 2 ) and in almost $65 \%$ for testing sample (Table reft3). Additionally, it should be taken under consideration how to reduce case "no incident - incident", the mistake in this case has the worst effects. However, if the model predict wrongly "incident" as negative result can be one more technical check.

Figure 5 shows the obtained results with the use of decision tress.

\section{Conclusions}

In order to properly assess the risks, information about aviation occurrences and their consequences is needed. In Polish Air Forced such information are stored in IT system TURAWA. This system gives the possibility to assess the severity and consequences of an air accidents. Thus the Airworthiness Risk Acceptance Matrix may be created thereafter.

With real data available from the operation process, quantitative and qualitative risk estimation methods, that complement each other, can be used. Airworthiness Risk Acceptance Matrix method based on the expert knowledge. In order to reduce the human factor error, statistical method has been proposed in this contribution.

There are some practical and theoretical issues that need to be taken into account in the future work. The use of tools such as fuzzy logic and statistical reasoning may in the future allow to obtain more accurate results.

\section{References}

[1] M. Hinz, F. Hienzsch, S. Bracke, Development of two methods for the characterisation of an automotive fleet behaviour based on the simulation of single car rides, in Risk, Reliability and Safety: Innovating Theory and Practice (Glasgow, Scotland, 2017), pp. 1593-1598

[2] V.Y. Kozhevnikov, N. Semeniuk, A.V. Kozyrev, V.M. Karaban, D.S. Kosov, Novel automated software system for arcing simulation in spacecraft on-board electronics, in 2017 2nd International Conference on System Reliability and Safety (ICSRS) (2017), pp. 469-473

[3] Z. Vintr, D. Valis, Vehicle maintenance process optimization using life cycle costs data and reliabilitycentered maintenance, in Proceedings of the First International Conference on Maintenance Engineering (2006), pp. 180--188

[4] V.Y. Kozhevnikov, A.V. Kozyrev, N.S. Semeniuk, A.V. Batrakov, V.M. Karaban, D.S. Kosov, Design and diagnostics of arc-resistant electronics for satellite telecommunication systems, in 2016 18th Mediterranean Electrotechnical Conference (MELECON) (2016), pp. 1-5

[5] Z. Vintr, D. Valis, A Tool for Decision Making in KOut-of-N System Maintenance, in Mechanical and Aerospace Engineering, ICMAE2011 (Trans Tech Publications, 2012), Vol. 110 of Applied Mechanics and Materials, pp. 5257-5264

[6] M. Woch, Reliability analysis of the PZL-130 Orlik TC-II aircraft structural component under real operating conditions, in Eksploatacja i Niezawodnosc - Maintenance and Reliability (2017), Vol. 19(2), p. 287-295

[7] E.J. Tuegel, R.P. Bell, A.P. Berens, T. Brussat, J.W. Cardinal, J.P. Gallagher, J. Rudd, Aircraft Structural Reliability and Risk Analysis Handbook, Volume 1: Basic Analysis Methods (Air Force Research Laboratory, Ohiao, 2013)

[8] A.V. Kozyrev, V.Y. Kozhevnikov, N.S. Semeniuk, L.A. Zyulkova, Theoretical Simulation of a Gas Breakdown Initiated by External Plasma Source in the Gap With Combined Metal-Dielectric Electrodes, in IEEE Transactions on Plasma Science (2015), Vol. 43, pp. 2294-2298, ISSN 0093-3813

[9] J. Zurek, Z. Smalko, M. Zieja, Methods applied to identify causes of air events, in Reliability, Risk And Safety: Theory And Applications vols 1-3 (2010), Vol. 1-3, pp. 1817-1822

[10] E.J. Tuegel, R.P. Bell, A.P. Berens, T. Brussat, J.W. Cardinal, J.P. Gallagher, J. Rudd, Aircraft Structural Reliability and Risk Analysis Handbook, Volume 1: Basic Analysis Methods (Air Force Research Laboratory, Ohiao, 2013)

[11] (Electronic Version): StatSoft, Inc., Electronic Statistics Textbook (OK: StatSoft, Tulsa, 2013), http: //www. statsoft.com/textbook/

[12] A. Mueller, M. Hinz, S. Bracke, Optimization of the dental implant testing based on FEM simulation of fatigue and accelerated life, in Risk, Reliability and Safety: Innovating Theory and Practice (Glasgow, Scotland, 2017), pp. 16-22 


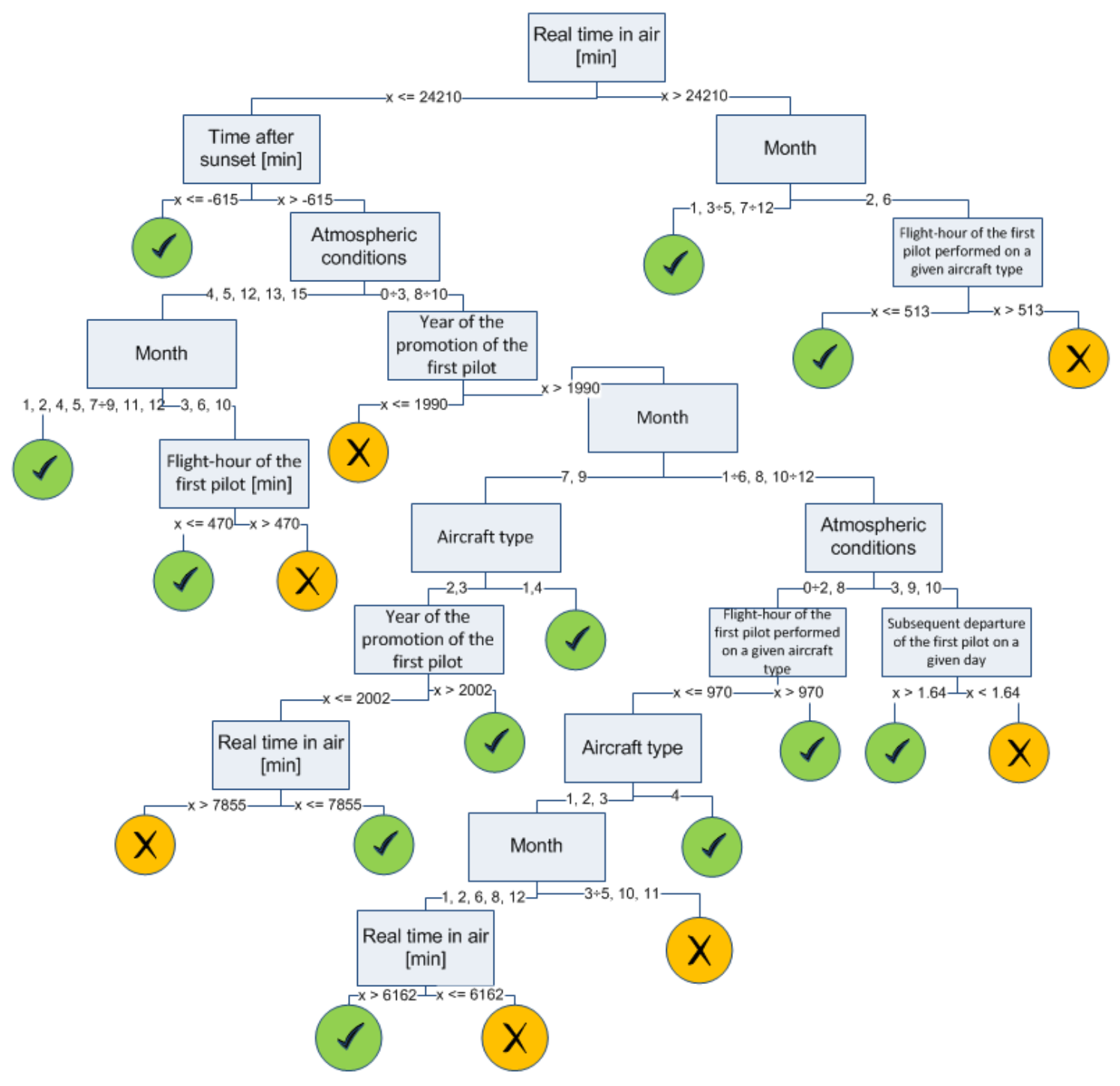

Figure 5. Sketch of the decision tree.

[13] B. Babiarz, Reliability analysis in subsystem of heat supply, in 2016 International Conference on Information and Digital Technologies (IDT), edited by IEEE (Rzeszow, Poland, 2016), pp. 11-16

[14] M. Hinz, F. Hienzsch, S. Bracke, Detection of Distinctions in Car Fleets Based on Measured and Simulated Data, in RAMS 2017-63rd Annual Reliability and Maintainability Symposium (Orlando, Florida, U.S.A., 2017)

[15] Z. Vintr, D. Valis, Modeling and Analysis of the Reliability of Systems with One-shot Items, in 2007
Annual Reliability and Maintainability Symposium (2007), pp. 380-385, ISSN 0149-144X

[16] B. Babiarz, An introduction to the assessment of reliability of the heat supply systems, in International Journal of Pressure Vessels and Piping, edited by Elsevier (2006), Vol. 83 (4/2006), pp. 230-235

[17] P. Golda, M. Zieja, Risk Analysis in Air Transport, in Transport Means 2015, pts I and II, Transport Means - Proceedings of the International Conference (2015), pp. 620-623 